\title{
Using Prewriting Tasks in L2 Writing Classes: Insights from Three Experiments
}

\author{
Kim McDonough \& Heike Neumann
}

Even though collaborative prewriting tasks are frequently used in second language (L2) writing classes (Fernández Dobao, 2012; Storch, 2005), they have not been as widely researched as other tasks, such as collaborative writing and peer review. This article examines the effectiveness of collaborative prewriting tasks at encouraging English for Academic Purposes (EAP) students to engage in critical reflection while brainstorming the content and organization of written texts. Drawing upon data from three experiments (Neumann \& McDonough, 2014a, 2014b), the impact of task design and students' perceptions about collaboration on their prewriting discussions are explored. Suggestions for instructors with an interest in using collaborative prewriting tasks are provided.

Les tâches collaboratives de préparation à la rédaction sont communes dans les cours de rédaction en langue seconde (Fernández Dobao, 2012; Storch, 2005); par contre, elles n'ont pas aussi souvent fait l'objet de recherche que d'autres tâches comme la rédaction collaborative et l'examen par les pairs. Cet article examine dans quelle mesure les tâches collaboratives de préparation à la rédaction encouragent les étudiants en anglais académique à réfléchir de façon critique pendant les séances de remue-méninges sur le contenu et l'organisation de textes écrits. Puisant dans des données découlant de trois expériences (Neumann \& McDonough, 2014a, 2014b), nous explorons l'impact qu'ont l'élaboration de la tâche et les perceptions des étudiants quant à la collaboration sur leurs discussions pendant la préparation à la rédaction. En fin d'article, nous présentons des suggestions qui visent les enseignants intéressés à employer des tâches collaboratives de préparation à la rédaction.

Numerous studies have shown that second language (L2) learners scaffold each other during a variety of pair and small group activities in L2 classrooms, such as dictogloss tasks, decision-making and information-exchange tasks, consciousness-raising activities, and picture narration tasks. In L2 writing classes specifically, commonly used tasks include peer review of written texts (Hu \& Lam, 2010; Liu \& Sadler, 2003; Lundstrom \& Baker, 2009; Min, 2006), collaborative writing (Storch \& Aldosari, 2010, 2013; Wigglesworth \& Storch, 2009), and collaborative prewriting tasks (Neumann \& McDonough, 2014a, 2014b; Shi, 1998). Collaborative tasks are believed to create learning opportunities when students negotiate meaning, provide each other with feedback, and produce modified output in order to successfully communicate meaning (Gass, 2003; Long, 1996; Mackey, 2012). Task interaction also creates 
social contexts that encourage students to contribute aspects of language and content to the conversation in ways that help them appropriate new knowledge and consolidate their existing knowledge (Lantolf, 2011; Swain, 2006).

Although much of the L2 task research has focused narrowly on the types of language that students discuss while they are collaborating (i.e., grammar, vocabulary, spelling), a few studies have taken a more global perspective to explore whether students also discuss the content and organization of the texts they are writing (Elola \& Oskoz, 2010; Storch, 2005; Storch \& Wigglesworth, 2007; Wigglesworth \& Storch, 2009). The findings of these studies have shown that L2 students spend the majority of their time on the composing process (as opposed to planning or revising), and they discuss content most frequently, along with language and organization. Despite their effectiveness at encouraging students to discuss content, organization, and language, collaborative writing tasks are not used widely in our educational context-English for Academic Purposes (EAP) writing classes - due to time constraints and grading issues. Instructors do not have enough class time to administer collaborative writing tasks, which generally take students longer to complete than individual writing tasks (Storch, 2005). Furthermore, because students' EAP writing class grades count toward their overall grade point average, there is often a preference for individual assessment rather than pair or group assessment tasks because of issues with fairness and reliability of group assessments (Kagan, 1995; Strauss \& U, 2007).

As part of our overall research agenda to create effective tasks for use in our EAP writing classes, we were interested in whether collaborative prewriting tasks provided students with opportunities to discuss and evaluate content and organization, while still maintaining the programmatic emphasis on individual writing. In other words, the tasks allowed students to collaborate during the planning phase, but they individually composed written texts that were assessed as part of their class grade. Our own pilot study on prewriting discussions confirmed Storch's (2005) finding that students pay attention to language mostly in the composing and revising phases but not during the brainstorming and planning phase. For this reason, we focused narrowly on students' engagement with content and organization as part of the planning phase. Even though collaborative prewriting discussions are frequently used in L2 writing classes (Fernández Dobao, 2012; Storch, 2005), they have not been researched as extensively as collaborative writing or individual prewriting tasks. For this In the Classroom article, we highlight key findings from three experiments that investigated the nature of student talk during collaborative prewriting discussions (Neumann \& McDonough, 2014a, 2014b), and explore whether task design and students' perceptions about collaboration affect their engagement in critical reflection. Following an overview of the students and the EAP writing class, we describe the students' interaction that occurred in each experiment and conclude with some observations about the use of collaborative prewriting tasks in EAP writing classes. 


\section{Participants and Instructional Setting}

Across the three experiments, the participants were English L2 students ( $N$ = 63) who were enrolled in undergraduate $(98 \%)$ or graduate $(2 \%)$ degree programs at Concordia University in Montreal. They had already partially met the university's English proficiency requirement for admission, which was a TOEFL iBT (Internet-based test) score between 75 and 89 or equivalent, but based on their performance on the university placement test, the students were required to take the first of two English for Academic Purposes (EAP) writing courses. They represented a variety of L1 backgrounds: Chinese (25), Arabic (10), French (7), Portuguese (4), Farsi (3), Spanish (3), Romanian (2), Russian (2), Vietnamese (2), Bangla (1), Korean (1), Pashto (1), Turkish (1), and Urdu (1). The students were working toward degrees in the faculties of Business (30), Engineering and Computer Science (18), and Arts and Sciences (15).

The students' required EAP writing class was taught by the second researcher, and it met for two, 23/4-hour classes per week over a 13-week semester. The EAP class focused on the development of general academic language skills, including reading strategies, review of vocabulary and grammatical structures useful for understanding and composing academic texts, and theme-based, paragraph-level writing tasks. The class was organized into 11 thematic chapters, with each chapter containing a variety of reading texts related to the chapter theme, vocabulary and grammar explanation and practice, and a paragraph-level writing activity. Each paragraph writing assignment was graded by the instructor using an analytical rating scale, and contributed $2.5 \%$ toward the students' final grade. There were no changes in the curriculum, textbook, or assessment between the semesters in which the three experiments were carried out, which were Winter 2011, Fall 2012, and Winter 2013.

\section{Experiment 1: Unstructured Prewriting Discussions}

Experiment 1 was an exploratory pilot study to identify the types of collaborative oral activities typically used in the EAP class. Every class was videorecorded, and 8-10 audio-recorders were placed around the classroom to capture students' interaction. When the instructor assigned collaborative activities, the students selected their own partners whom they felt comfortable working with and worked in groups of 2-4 students, with an audio-recorder nearby. For the prewriting discussions, the instructor asked the students to review the key topics and texts that had been covered in the chapter in order to brainstorm and consolidate ideas that they could use in a subsequent writing assignment. However, she did not tell the students details about the writing prompt and did not intervene in the students' discussion; she only provided assistance when students specifically requested her help. 
At the end of the semester, audio-recordings of the five classes with prewriting discussions were transcribed and verified by research assistants. A list of the topics and writing assignments for the prewriting discussions are provided in Appendix A. The transcripts were segmented into episodes that were about content (a main idea plus any reasons or supporting details) and organization (grouping, ordering, or linking of ideas). We were interested in how much of the student talk contained evaluation, feedback, or reflection, so we further classified the episodes as being either reflective or nonreflective. Following Higgins, Flower, \& Petraglia (1992), reflective episodes included explicit evaluation, consideration of alternatives, or justification, as shown in Episode 1 with data from the Overcoming obstacles prewriting discussion:

Episode 1: Reflective content

S1:

yeah so in one term he got his diplomas ... in only one and a half years

S8: I don't think that's our teacher's meaning. I don't think the teacher want us write about somebody who was on TV. Just we know of.

S1: familiar?

S8:

yeah

S1: she want us to write her a real person

S8: yeah I think but I can't find a person worth to write about. I think most of my friends and my relatives are normal

In contrast, nonreflective episodes did not contain these elements, as evident in Episode 2 from the Education prewriting discussion.

Episode 2: Nonreflective content

$\begin{array}{ll}\text { S11: } & \text { okay can we turn to the second one? } \\ \text { S1: } & \text { yes } \\ \text { S10: } & \text { financial resources } \\ \text { S11: } & \text { yes we should have necessary supplies } \\ \text { S1: } & \text { okay }\end{array}$

If students simply shared personal experiences related to the course themes without evaluation, alternative plans, justification, or an explicit link to the writing assignment, the episodes were coded as nonreflective.

The data for Experiment 1 consisted of 15 prewriting discussions involving 19 students. Each discussion lasted from 15 to 20 minutes, and there were $2-4$ discussion groups per topic with $2-4$ students per group. There were a total of 105 content episodes in the transcripts (an average of seven episodes per discussion group), and there were no organization episodes in the entire dataset. The majority of the content episodes $(80 \%)$ were nonreflective, with only a minority (20\%) involving any critical reflection, evaluation, or justifi- 
cation. The prevalence of nonreflective content episodes may be due to the fact that the students found it natural to simply listen to each other's ideas. Without any details about the writing prompt or specific instructions to critically engage with their peers' ideas and comments, students may have opted to simply chat about their personal beliefs and opinions. Although the instructions for three of the five prewriting discussions specified that students should organize their ideas, they only talked about content. The transcripts included several instances in which the students were trying to guess what the writing prompt would be and locate relevant information in the class textbook, such as readings or vocabulary words.

Based on the findings of Experiment 1, we decided to create structured prewriting tasks in an attempt to encourage the students to engage in more critical reflection and evaluation of both content and organization. We decided to give the students the writing prompt before they carried out the task so they could understand that the purpose of the prewriting task was to prepare them to write. The emphasis on reflection and critical evaluation was made more explicit in the task instructions in an attempt to push the students to justify their ideas and choices. A separate section in the task materials was created to focus specifically on the organization of ideas into a writing plan. The goal of Experiment 2, therefore, was to investigate whether the structured prewriting task was more effective at eliciting reflective content and organization episodes than the prewriting discussions analyzed in Experiment 1.

\section{Experiment 2: Structured Prewriting Tasks}

Six structured prewriting tasks were created, which corresponded to the five topics used in Experiment 1, plus an additional topic (see Appendix A). Each structured prewriting task had three sections: a statement of the writing topic and list of relevant resources in the textbook, an area for writing down ideas, and an area for planning a simple bullet outline. After students individually brainstormed some ideas and wrote them on the task handout, they then collaborated in groups to share ideas. The instructions explicitly stated that they should give their peers feedback about the appropriateness of the ideas for the writing assignment, and the task materials included a column where students could write down the evaluative comments they received. Once they finished exchanging and evaluating ideas, the students individually completed a bullet outline on their handouts. The final activity was to share their outlines and provide each other with feedback. The structured collaborative prewriting task for the writing assignment about family living is provided in Appendix B as an example.

The instructor implemented the structured collaborative prewriting tasks by reviewing the instructions on the task materials and asking students to self-select groups of 2-4 students in order to ensure they felt comfortable 
working with their team members. Once the instructor had set up the collaborative prewriting tasks, she did not intervene in the students' discussions and only responded to specific requests for assistance. Each task took from 20 to 30 minutes to complete, including both the individual brainstorming and group discussions. Audio-recordings of the group discussions were transcribed and verified by research assistants. The transcripts were analyzed to identify content and organization episodes only, which were further classified as reflective or nonreflective using the same coding categories from Experiment 1.

The data for Experiment 2 consisted of 40 prewriting discussions involving 23 students, with 6-7 discussion groups per writing assignment with 2-4 students per group. There were 489 content and organization episodes in the entire dataset (an average of slightly more than 12 episodes per group). Content episodes were more frequent (78\%) than organization episodes (12\%). Of the 429 content episodes, $77 \%$ were nonreflective while $23 \%$ involved evaluation, justification, or alternatives. For the 60 organization episodes, $53 \%$ were nonreflective while $47 \%$ were reflective. There was an increase in the mean number of episodes per group (from 7 in Experiment 1 to 12 in Experiment 2 ), and a slight increase in the percentage of reflective content episodes: from $20 \%$ to $23 \%$. Compared to Experiment 1, when no organization episodes occurred, the structured prewriting tasks were more effective at eliciting student talk about organization, with nearly half of those episodes involving evaluation, justification, or alternatives.

Based on the findings of Experiment 2, we concluded that including a separate section about organization was an effective way of encouraging students to discuss how they would present their ideas in the writing assignment, such as the order of the ideas to mention, the use of examples to support main points, and the links between ideas. Furthermore, nearly half of the organization episodes were reflective, which means that the students provided each other with feedback, evaluative comments, and justification for their writing plans. However, the structured prewriting task was only marginally more successful at eliciting reflective content episodes than the prewriting discussions used in Experiment 1. One possible explanation for this is that the prewriting process simply lends itself to the generation of multiple ideas, with only a fraction selected as worthy of further evaluation or reflection. In other words, students brainstorm numerous ideas that they share with their peers, but they critically engage with only a subset of those ideas, specifically the ones they believe are good enough to include in the writing assignment. Another possibility, however, is that the overall percentage of reflective content episodes is low simply because some students may not view their peers as sources of valuable feedback. If students do not perceive peer interaction as useful for their writing development, they may minimally engage with each other's ideas, thereby resulting in a low percentage of reflective content episodes. Therefore, as part of a larger study, Experiment 3 
examined whether students with positive orientations toward collaborative tasks produced more reflective episodes during structured prewriting tasks.

\section{Experiment 3: Collaboratively-Oriented Students and Structured Prewriting Tasks}

In Experiment 3 we explored whether students with a positive orientation toward peer collaboration produced more reflective content and organization episodes during structured prewriting tasks. A background questionnaire administered by a research assistant without the instructor present contained four items utilizing a 9-point Likert scale $(1=$ not helpful; $9=$ very helpful $)$ to ask students how valuable it was to work with peers in order to (a) understand an assignment, audience, and purpose, (b) brainstorm ideas, (c) evaluate which ideas to write about, and (d) organize ideas into a prewriting plan. All students participated in the prewriting discussions, but for our analysis we focused on students who scored high on these questionnaire items (average rating $=8.5$ ) and then selected discussion groups that had at least two collaborative-oriented members. Only three of the six structured prewriting tasks designed for Experiment 2 (obstacles, collective living, and family living) were implemented collaboratively in Experiment 3, and they were administered following the same procedures used in Experiment 2.

The dataset consisted of 10 collaborative prewriting discussions on these three topics, with 2-4 discussion groups per topic involving 21 students. There were 2-3 students per group. There were a total of 100 content and organization episodes in the dataset (an average of 10 episodes per group), with almost all episodes about content (95\%). Of the 95 content episodes, $74 \%$ were nonreflective and $26 \%$ were reflective, which represents a slight increase over Experiment 2 (23\%). Although only five organization episodes occurred, they were all reflective. Thus, the findings from Experiment 3 suggest that even students who highly value peer collaboration as part of the prewriting phase produce a large number of nonreflective content episodes. This suggests that the prevalence of nonreflective content episodes during prewriting discussions (both unstructured and structured) may be due to the nature of prewriting, as opposed to a lack of interest in peer collaboration.

\section{General Discussion}

Figure 1 summarizes across the three experiments. Experiment 1 showed that simply asking students to discuss content and organization before giving them a writing assignment was not particularly effective at eliciting critical reflection or evaluation, particularly about organization. After improving the task design, the structured prewriting tasks used in Experiment 2 elicited more reflective content episodes and successfully elicited evaluative talk about organization. 


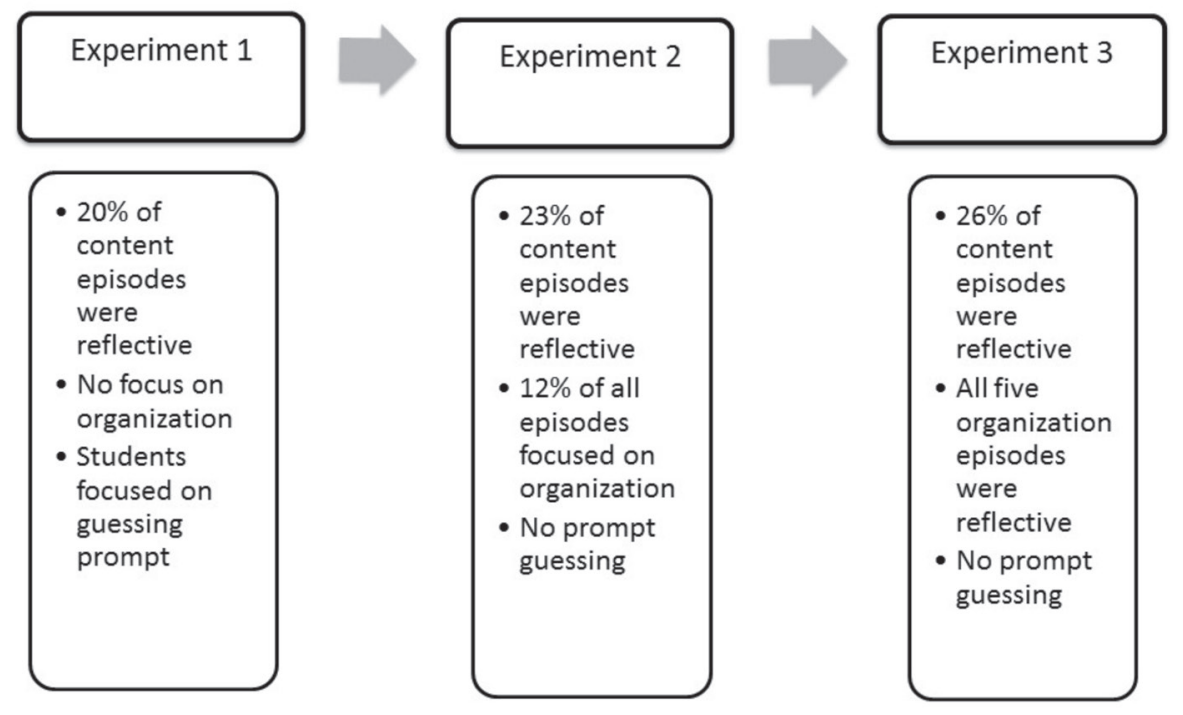

Figure 1. Key findings across experiments

To explore whether the quantity of reflective episodes was related to students' perceptions about the value of peer interaction, Experiment 3 focused on students who rated peer collaboration highly. Despite having at least two out of three collaboratively oriented students in each group, the structured prewriting tasks elicited only slightly more reflective content episodes than they did in Experiment 2. Taken together, the findings suggest that both task design and students' beliefs about the value of peer collaboration may influence the degree to which they critically engage with their peers' ideas during collaborative prewriting tasks. However, the relatively consistent percentage of reflective content episodes across the three experiments (20-26\%) suggests that although prewriting discussions may inherently elicit a large number of ideas, students critically engage with only a subset of their ideas.

In terms of task design, the contrasting findings in Experiments 1 and 2 suggest that providing students with structured tasks may be more effective than general instructions. The prewriting discussions in Experiment 1 included oral instructions to talk about content and organization and did not provide details about the writing assignment. Based on the amount of student talk during Experiment 1 to clarify the purpose of the discussion, locate information in the textbook, and speculate about the writing assignment, we concluded that a more structured task may be necessary. By providing students with more information about the purpose of the prewriting discussion, the writing prompt, and relevant resources in a handout with separate sections for content and organization, we made the structured task more effective, particularly for eliciting discussion about organization. In order for prewriting tasks to help students generate content and organize their ideas, 
it may be useful to make the purpose of the activity explicit to students (both orally and on task materials), separate the content and organization components, and give students time to individually brainstorm before engaging in peer collaboration.

In terms of students' perceptions about collaboration, the quantity of reflective episodes did not differ dramatically between Experiments 2 and 3, even though the latter focused specifically on students who valued collaboration. As suggested previously, this may be due to the nature of prewriting activities, in which students generate many ideas but select only a few of them for extensive discussion. Another potentially mediating factor may be group dynamics, as has been found in Storch's collaborative writing research (2002a, 2002b) and other peer interaction studies (Kim \& McDonough, 2008, 2011; Watanabe \& Swain, 2007). In other words, while some groups adopted a collaborative approach, in which all students volunteer feedback and actively seek answers to their questions, other groups showed less interest in seeking or providing advice. Even if students value collaboration, their peer relationships may play an important role in the extent to which they engage with each other's ideas during structured prewriting tasks. For example, one collaboratively oriented student in Experiment 2 was an active participant during prewriting tasks when her group included like-minded peers, but she did not have the same level of engagement when she worked with students who had more negative perceptions of collaboration. Research to date has not identified whether it is more effective for instructors to take an active role in assigning students to groups (based on proficiency, L1 background, orientation toward collaboration, or other variables) or to allow students to self-select whom they would prefer to work with.

In conclusion, structured prewriting tasks may provide L2 writing instructors with an effective tool for exploiting the benefits of peer collaboration while maintaining a focus on individual writing development and assessment. As part of the larger studies, we also explored the relationship between the students' interaction and ratings of their individually written texts; a detailed discussion of those findings is available in the complete research reports (Neumann \& McDonough, 2014a, 2014b). The EAP classes examined here focused on paragraph-level texts, but structured prewriting tasks can easily be adapted for use with other kinds of written texts and genres. When adapting the tasks for other text types, it may be useful to maintain key elements of the structured task format, such as making the purpose explicit, emphasizing the importance of evaluation of ideas and organization, providing time for individual brainstorming prior to group discussion, and separating the components of the task into separate steps. When implementing structured prewriting tasks, it may be useful to follow Storch's (2013) suggestions for the use of collaborative writing tasks, such as modelling collaborative interaction, providing communication strategies for effective interaction, and monitoring group interaction. Our future research aims to confirm whether 
these techniques positively impact student interaction during structured prewriting tasks and further clarify whether prewriting discussions facilitate individual writing development.

\section{Acknowledgements}

This research was supported by funding from the Social Studies and Humanities Research Council of Canada (SSHRC, 410-2011-1416), the Canada Research Chairs program (CRC, 950-221304), and the Fonds québécois de la recherche sur la société et la culture (FQRSC, 2012-SE-144647). We would like to thank the research assistants for their help with data collection, transcription, and analysis: Zach Alderton, Yuan Chen, Rebecca Dorner, Jennifer Foote, Liana Jalyayan, Paula Kielstra, Jihoon Kim, Max Lavallee, Pham Quynh Mai Nguyen, Xuan Qin, and Fernanda Soler.

\section{The Authors}

Kim McDonough is an Associate Professor and Canada Research Chair in Applied Linguistics at Concordia University. Her research interests include interaction and usage-based approaches to second language acquisition, structural priming, low-variability input, and task-based language teaching.

Heike Neumann is a lecturer of English as a second language and a language test developer in the Department of Education at Concordia University. Her research interests include secondlanguage writing pedagogy, writing assessment, and language assessment.

\section{References}

Elola, I., \& Oskoz, A. (2010). Collaborative writing: Fostering foreign language and writing conventions development. Language Learning and Technology, 14(3), 51-71.

Fernández Dobao, A. (2012). Collaborative writing tasks in the L2 classroom: Comparing group, pair, and individual work. Journal of Second Language Writing, 21(1), 40-58.

Gass, S. (2003). Input and interaction. In C. Doughty \& M. Long (Eds.), Handbook of second language acquisition (pp. 224-255). Oxford, UK: Blackwell.

Higgins, L., Flower, L., \& Petraglia, J. (1992). Planning text together. Written Communication, 9(1), 48-84. doi: 10.1177/0741088392009001002

Hu, G., \& Lam, S. T. E. (2010). Issues of cultural appropriateness and pedagogical efficacy: Exploring peer review in a second language writing class. Instructional Science, 38(4), 371-394.

Kagan, S. (1995). Group grades miss the mark. Educational Leadership, 52(8), 68-71.

Kim, Y., \& McDonough, K. (2008). The effect of interlocutor proficiency on the collaborative dialogue between Korean as a second language learners. Language Teaching Research, 12(2), 211-234.

Kim, Y., \& McDonough, K. (2011). Using pre-task modeling to encourage collaborative learning opportunities. Language Teaching Research, 15(2), 183-199.

Lantolf, J. P. (2011). The sociocultural approach to second language acquisition: Sociocultural theory, second language acquisition, and artificial L2 development. In D. Atkinson (Ed.), Alternative approaches to second language acquisition (pp. 24-47). New York, NY: Routledge.

Liu, J., \& Sadler, R. W. (2003). The effect and affect of peer review in electronic versus traditional modes on L2 writing. Journal of English for Academic Purposes, 2(3), 193-227.

Long, M. H. (1996). The role of the linguistic environment in second language acquisition. In W. Ritchie \& T. Bhatia (Eds.), Handbook of second language acquisition (pp. 413-468). San Diego, CA: Academic Press.

Lundstrom, K., \& Baker, W. (2009). To give is better than to receive: The benefits of peer review to the reviewer's own writing. Journal of Second Language Writing, 18(1), 30-43.

Mackey, A. (2012). Input, interaction and corrective feedback in L2 learning. Oxford, UK: Oxford University Press. 
Min, H.-T. (2006). The effects of trained peer review on EFL students' revision types and writing quality. Journal of Second Language Writing, 15(2), 118-141.

Neumann, H., \& McDonough, K. (2014a). Exploring the relationships among student preferences, prewriting tasks, and text quality in an EAP context. Journal of English for Academic Purposes, 15, 14-26. doi: http://dx.doi.org/10.1016/j.jeap.2014.05.002

Neumann, H., \& McDonough, K. (2014b). Exploring student interaction during collaborative prewriting discussions and its relationship to L2 writing. Journal of Second Language Writing. First published online: November 4, 2014. doi: http://dx.doi.org/10.1016/j.jslw.2014.09.009

Shi, L. (1998). Effects of prewriting discussions on adult ESL students' compositions. Journal of Second Language Writing, 7(3), 319-345.

Storch, N. (2002a). Patterns of interaction in ESL pair work. Language Learning, 52(1), 119-158.

Storch, N. (2002b). Relationships formed in dyadic interaction and opportunity for learning. International Journal of Educational Research, 37(3-4), 305-322.

Storch, N. (2005). Collaborative writing: Product, process, and students' reflections. Journal of Second Language Writing, 14(3), 153-173.

Storch, N. (2013). Collaborative writing in L2 classrooms. Bristol, UK: Multilingual Matters.

Storch, N., \& Aldosari, A. (2010). Learners' use of first language (Arabic) in pair work in an EFL class. Language Teaching Research, 14(4), 355-375.

Storch, N., \& Aldosari, A. (2013). Pairing learners in pair work activity. Language Teaching Research, 17(1), 31-48.

Storch, N., \& Wigglesworth, G. (2007). Writing tasks: The effects of collaboration. In M. d. P. García Mayo (Ed.), Investigating tasks in formal language learning (pp. 157-177). Clevedon, UK: Multilingual Matters.

Strauss, P., \& U, A. (2007). Group assessments: Dilemmas facing lecturers in multicultural tertiary classrooms. Higher Education Research \& Development, 26(2), 147-161.

Swain, M. (2006). Languaging, agency, and collaboration in advanced second language proficiency. In H. Byrnes (Ed.), Advanced language learning: The contributions of Halliday and Vygotsky (pp. 95-108). London, UK: Continuum.

Watanabe, Y., \& Swain, M. (2007). Effects of proficiency differences and patterns of pair interaction on second language learning: Collaborative dialogue between adult ESL learners. Language Teaching Research, 11(2), 121-142.

Wigglesworth, G., \& Storch, N. (2009). Pair versus individual writing: Effects on fluency, complexity and accuracy. Language Testing, 26(3), 445-466.

\section{Appendix A Writing Topics}

\begin{tabular}{|c|c|}
\hline Topic & Writing Assignment \\
\hline Overcoming obstacles & $\begin{array}{l}\text { Write a paragraph about person from your life who experienced an } \\
\text { obstacle and describe how he/she overcame it. }\end{array}$ \\
\hline Socialization & $\begin{array}{l}\text { Write a paragraph in which you explain how one factor (family, } \\
\text { peers, or media) has most influenced you. }\end{array}$ \\
\hline Collective living & $\begin{array}{l}\text { Write a paragraph that explains whether the benefits of social liv- } \\
\text { ing outweigh the costs for humans. }\end{array}$ \\
\hline Education & Write a paragraph that explains your opinion about home schooling. \\
\hline Family living & $\begin{array}{l}\text { Write a paragraph that describes changes in family life (size, role } \\
\text { of women, or role of children). }\end{array}$ \\
\hline *Before/after vaccines & $\begin{array}{l}\text { Write a paragraph that compares and contrasts human life before } \\
\text { and after the invention of vaccines. }\end{array}$ \\
\hline
\end{tabular}

*This writing assignment was not included in Experiment 1. 


\section{Appendix B \\ Structured Prewriting Task}

Writing Topic:

Unit 7 "The Changing Nature of the Family"

You will write a paragraph in which you explain how family size (nuclear/

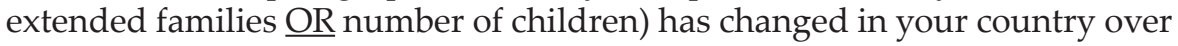
the last hundred years. In your paragraph, you will ...

... describe the change,

... explain one reason for this change, AND

... explain one consequence of this change.

Part 1: Generating \& Evaluating Ideas

a) Using the table below, take notes on how family size has changed. Focus either on whether families are nuclear or extended OR on how many children each family has. List the most important reasons for this change, including details on this reason. List several consequences of this change, including details of these consequences.

\begin{tabular}{|l|l|l|l|}
\hline $\begin{array}{c}\text { Description } \\
\text { of Change }\end{array}$ & $\begin{array}{c}\text { Reasons } \\
\text { for Change }\end{array}$ & $\begin{array}{c}\text { Consequences of } \\
\text { Change }\end{array}$ & $\begin{array}{c}\text { Feedback from } \\
\text { Group: } \\
\text { Information clear? }\end{array}$ \\
\hline & & & \\
\hline
\end{tabular}

b) Tell your group about the change in family size in your country. Explain the most important reason for this change and the most important consequence of this change.

c) As you listen to members of your group, evaluate and explain whether they have chosen good reasons and examples. As you receive feedback, record it in the table above.

Part 2: Selecting \& Organizing Ideas

a) Based on your group's feedback, choose what information you will include in your paragraph. What information will you mention in which order? Make an outline, and then share it with your group.

-

b) As you listen to your group's writing plans, give them feedback about whether their outline is well organized. 